\title{
Discursos curriculares da formação docente, projetos de trabalho e seus elos com a racionalidade neoliberal
}

\author{
Jaqueline de Menezes Rosa* \\ Maria Isabel Edelweiss Bujes**
}

\begin{abstract}
Resumo
O estudo propôs-se a problematizar a centralidade dos Projetos de Trabalhos nos currículos da formação docente atual. Submetendo o material empírico - um conjunto de textos dos livros mais utilizados nos cursos de Pedagogia da região metropolitana de Porto Alegre - a uma análise discursiva, inspirada em teorizações de cunho pós-estruturalista de acento foucaultiano, faz-se inicialmente uma articulação entre a discursividade pedagógica da Modernidade e os ideais liberais. Adicionalmente tal discursividade é articulada a um conjunto de estratégias pedagógicas do presente, vistas, a partir do referencial teórico como práticas de administração das condutas, tanto de professores quanto de alunos. Ao longo da análise ressalta-se a associação dos Projetos de Trabalho a formas de governamento dirigidas a sujeitos ideais nas diversas expressões do liberalismo, potencializando a governamentalização da sociedade. Investir, nos cursos de formação, na proposta dos Projetos pode ser visto também como investimento em capital humano, prática esta que visa promover a maximização dos potenciais de cada um, sendo útil tanto para a constituição subjetiva dos docentes, quanto para o alcance das metas do projeto neoliberal.
\end{abstract}

Palavras-chave: Projetos de Trabalho; currículo da formação docente; discursos; governamento; (neo)liberalismo.

\section{Teacher's education curricular discourses, project methods and it's links to a neoliberal rationality}

\begin{abstract}
This investigation intends to problematize the centrality of project methods in current teacher's education curricula. Submiting empirical material - an array of texts from books largely used in Pedagogy courses in the metropolitan region of Porto Alegre - to a discursive analysis, inspired on post-structuralist theories and Michel Foucault's ideas, an articulation is made between Modernity's pedagogical discursivity and liberal ideals. Aditionally such discursivity is articulated to a set of today pedagogical strategies seen, due to the investigation theoretical framework, as practices to administrate teachers and pupils conducts. Along the analysis the association of project methods to government practices is stressed showing that it is directed to diversified expressions of ideal subjects under liberalism, thus contributing to potentialize society's governmentalization. The emphasis on project methods in teacher's education can be seen as an investment on human capital, practice that intends to maximize each one's potential, promoting the subjective constitution of teachers as well as the goals of the neoliberal project.
\end{abstract}

Keywords: Project methods; teacher's education curricula; discourses; government; (neo)liberalism.

\section{Apresentação}

As questões educacionais estão, hoje, na ordem do dia. Grande parte dos problemas sociais trazidos à discussão aparecem de alguma forma associados a discursos que pautam fragilidades dos processos educativos. Num registro que oscila da responsabilização da escola por inúmeros insucessos sociais a posicionamentos salvacionistas, que creditam a ela a superação dos descaminhos de toda ordem, pode-se inferir o papel crucial que a instituição escolar vem representando para a manutenção da ordem moderna. À inoperância dos sistemas formais de ensino tanto se atribui a responsabilidade pelas situações problemáticas atuais, as mais variadas, quanto a culpa por não preparar de modo satisfatório as crianças e jovens para ocupar

\footnotetext{
* Endereço eletrônico: jaque.pocas@terra.com.br

** Endereço eletrônico: mibujes@ terra.com.br
}

competentemente, no futuro, as posições políticas e sociais e os postos de trabalho de que o país estaria a precisar. Frente a esse quadro de mazelas, proliferam sugestões de enfrentamento para aquilo que vem sendo considerado genericamente como um déficit de qualidade da escola brasileira. Soluções que passam por reformas do sistema educacional, implantação de avaliações nacionais, projetos de formação e aperfeiçoamento de professoras/es, reorganização dos quadros docentes, recomposição de planos de carreira e de matrizes salariais, entre tantas outras que seria demasiado enumerar, são anunciadas e/ou postas em execução neste afã de reformar a educação e, por meio dela, dar conta de uma miríade de problemas sociais que the seriam correlatos. 
Sem pretender empreender uma discussão sobre o diagnóstico ou as perspectivas de enfrentamento dos problemas enunciados brevemente no parágrafo anterior, buscamos situar o trabalho aqui apresentado numa perspectiva muitissimamente mais modesta, atendo-nos ao campo curricular e pedagógico (ainda que sem desconhecer suas viscerais articulações com o sistema político e social, como se verá mais adiante). O que chama nossa atenção, e que constituirá o foco do que nos propomos a discutir, é o modo como ganha força no currículo de formação de professoras a proposição de uma estratégia pedagógica na qual parecem repousar infinitas esperanças, capaz de fazer frente às questões de aprendizagem, na busca de romper com ciclo em que a figura docente é central. $\mathrm{O}$ que nos instiga é a proposta amplamente disseminada de preparação das docentes para a adoção, nas instituições escolares de todos os níveis, dos chamados Projetos de Trabalho. Os Projetos de Trabalho, segundo os seus defensores, seriam representativos de uma escolha racional e de um compromisso em constituir uma sociedade de aprendizagem, de "[...] um modo de viver pelo uso da razão, como um processo contínuo de resolução de problemas, no qual o indivíduo est[aria] ligado ao bem coletivo da sociedade" (POPKEWITZ; OLSSON; PETERSSON, 2009, p.74).

Desafiadas, portanto, a compreender como certas formas de intervenção pedagógica tornam-se expressão de interesses que correspondem a objetivos colocados no nível da administração das populações, propomos neste trabalho, que decorre de investigação que detalharemos mais adiante: a) analisar como determinadas propostas metodológicas/tecnologias educativas envolvem pensar e encontrar modos de agir e de intervir sobre atitudes, disposições e comportamentos dos alunos de forma a ajustar suas condutas a objetivos sociais amplos, proclamados como de interesse coletivo; b) discutir como a invenção de certas práticas pedagógicas ganha relevo ao articular-se a preocupações sociais correntes e por corresponder a uma dinâmica global que lhes dá sentido.

Para dar conta de tais propósitos, vamos nos valer de algumas ferramentas teóricometodológicas oferecidas pela notável caixa de ferramentas de Michel Foucault e, orientadas por uma perspectiva pós-estruturalista, dialogaremos com teorizações de autores que vêm atualizando as análises por ele empreendidas. Nas discussões sobre temas do presente, referentes ao campo educativo, em geral, e ao da escolarização, em particular, recorreremos a Alfredo Veiga-Neto, Thomas Popkewitz, Jorge do Ó e muitos outros. As ferramentas conceituais às quais nos referimos são as noções de governamento e governamentalidade e, adicionalmente, de disciplinamento e biopoder/biopolítica.

A pretensão mais geral do trabalho é, portanto, por em evidência o compromisso da instituição escolar com a gestão da vida social, tornando mais explícitos os compromissos entre escolarização e relações de poder. Para atingir tal propósito colocamos em destaque as relações entre discursos curriculares da formação docente e a racionalidade política que domina as práticas sociais de nosso presente: o neoliberalismo.

\section{O escopo da pesquisa}

Tomamos como ponto de partida desta seção, em que pretendemos apresentar o escopo da pesquisa que dá origem a este texto, as palavras com as quais Popkewitz problematiza a questão das relações entre poder e saber nas práticas sociais: "O poder se pratica menos pela força bruta e mais pelos sistemas de saberes e da razão, no interior dos quais os objetos da escola são modelados, a fim de serem compreensíveis e capazes de passar para a ação" (POPKEWITZ, 2008, p. 236).

Michel Foucault é bastante emblemático em sua obra ao dizer que há uma relação entre essas duas instâncias, o que não significa que sejam idênticas. Distanciando-se das definições tradicionais de poder e saber, inverte a articulação de que o poder é apenas negativo. Em suas palavras: "temos de deixar de descrever sempre os efeitos de poder em termos negativos: ele 'exclui', 'reprime', 'recalca', 'censura', 'abstrai', 'mascara', 'esconde'. Na verdade, o poder produz; ele produz realidade; produz campos de objetos e rituais de verdade" (FOUCAULT, 2008a, p.161). A partir de uma teorização de inspiração foucaultiana, para a qual saber e poder se implicam mutuamente, interessamo-nos em problematizar os jogos de verdade presentes nos discursos de formação docente, sobretudo aqueles que se referem ao fazer educativo, sem a pretensão de interpretar o que estaria subjacente a eles. Entendemos que tal material tem uma constituição histórica e que a sua linguagem dá sentido às práticas de escolarização.

Ao problematizarmos as pesquisas sobre a formação docente, o enfoque dado aos saberes da prática, o vínculo entre experiência e discurso como centros do trabalho pedagógico, colocamos em questão a noção de que o professor, segundo uma visão hermenêutica, é a "[...] origem das 
operações de discursos e não o seu produto" (DÍAZ, 1999, p.19). A partir das análises inspiradas nas leituras do filósofo francês Michel Foucault, é possível discutir essa perspectiva. Os atos discursivos individuais estão atravessados por muitas "vozes", em uma permanente reescritura, expressão de campos discursivos institucionalizados. Em outras palavras, o discurso pedagógico não estaria relacionado a vontades ou individualidades autônomas, mas às práticas que organizam a realidade (FOUCAULT, 1996), a procedimentos que controlam e regulam o fazer pedagógico e ao que se diz sobre ele, frutos de relações de poder.

Começamos, assim, a pensar os saberes da Pedagogia e seus efeitos na conduta dos professores em formação, pois é notável, entre estes, o desenvolvimento de práticas que partilham, de certa forma, um mesmo referencial a respeito da escola e da aprendizagem. Há, a partir de vocabulários profissionais compartilhados, certos modelos de raciocínio que passam a ser universalizados. Não se trata aqui apenas de uma questão terminológica, como aponta Larrosa (2002). As palavras, os vocabulários compartilhados entre os profissionais da educação exprimem "lutas em que se joga algo mais do que simplesmente palavras, algo mais que somente palavras" (p.21). Isso possibilita pensar que as palavras vão adquirindo sentidos e significados em diferentes práticas, nas quais determinados grupos buscam impor seus modos de pensar o mundo, as relações sociais, o papel da escola etc.

Assim, se a formação docente passa a ser o nosso interesse primordial, os discursos em que a docência está implicada tornam-se matériaprima para esta investigação. $\mathrm{O}$ foco deste trabalho, portanto, direciona sua atenção para os discursos da formação, para o modo como os currículos dos cursos de Pedagogia, ao serem vertidos em programas e reinterpretados pelos seus atores, podem contribuir para nossa compreensão das dinâmicas sociais do presente.

Nesse sentido, tomamos como corpus de análise os livros que aparecem de forma recorrente nas bibliografias básicas e recomendadas de cursos de Pedagogia, referenciados nas disciplinas de Didática ou similares $^{1}$, de três universidades da região metropolitana de Porto Alegre. Foi preciso, então, selecionar os livros e tomar como critério de escolha aqueles mais utilizados nas três universidades. Com essa tarefa, foi possível apontar títulos que são recorrentes na bibliografia recomendada por essas instituições.

Os levantamentos iniciais apontaram como mais utilizados os seguintes livros: 1)
HERNÁNDEZ, Fernando; VENTURA, Montsserrat. A organização do currículo por Projetos de Trabalho: o conhecimento é um caleidoscópio. Porto Alegre: Artmed, 1998; 2) HERNÁNDEZ, Fernando. Transgressão $e$ mudança na educação: os projetos de trabalho. Porto Alegre: Artmed, 1998; 3) SACRISTÁN, J. Gimeno. $O$ currículo: uma reflexão sobre a prática. Porto Alegre: Artmed, 2000; e 4) SANTOMÉ, Jurjo Torres. Globalização e interdisciplinaridade: o currículo integrado. Porto Alegre: Artmed, 1998.

O interessante é perceber que tais obras, apesar de suas características próprias e de várias diferenças em suas proposições, permitem entrever um conjunto de enunciados que, como regras, se repetem nas teorizações dos autores. Há, ao que tudo indica na leitura dos livros aqui analisados, um tema comum que parece permear de modo bastante particular o conjunto das propostas dos autores. Trata-se do tema dos Projetos de Trabalho, centralizador do discurso da atividade docente, que aqui nos propomos a problematizar. Este tema nos ofereceu possibilidades de analisar algumas rupturas e redefinições nos discursos que vêm produzindo o sujeito professor na atualidade, bem como questionar alguns significados da docência presentes nas práticas históricas de formação não apenas direcionadas às subjetividades docentes, mas também a metas políticas mais amplas.

Nas seções a seguir, passamos a tratar da densidade e da amplitude do problema, tomando a Pedagogia e os discursos pedagógicos como "produto[s] de um complexo processo de definição [...], resultado[s] de um processo de construção social [que] depende[ra]m de um conjunto de possibilidades que se conjuga[ra]m em determinado momento da história [...]" (BUJES, 2001, p. 26). Isso significa que os discursos sobre os "Projetos de Trabalho", aqui analisados, não são naturais ou dados: são aquilo que pode ser dito dentro de certas matrizes ou modelos orientados pelos saberes de uma determinada época. E, ao adentrarmos um espaço que vem constituindo determinadas formas de ser professor, tratamos de buscamos perceber como se articularam interesses e estratégias de poder com os discursos que se servem dos ideais liberais na produção da docência contemporânea.

\section{O governamento da docência}

Colocar sob análise alguns dos discursos que circulam na formação de professores não envolve apenas examinar as relações de tais discursos com orientações para a prática futura, 
tais como noções sobre o que fazer e o que conhecer nos ambientes educativos. Envolve também as disposições, consciência e sensibilidade (POPKEWITZ, 1994) que eles pretendem forjar nos docentes em relação ao campo que está sendo descrito (atitudes apropriadas, formas particulares de agir).

"A idéia do currículo corporifica uma organização particular do conhecimento pela qual os indivíduos devem regular e disciplinar a si próprios [...], é uma imposição do conhecimento do 'eu' e do mundo [...]" (POPKEWITZ, 1994, p.186). Como um sistema de regulação, o currículo orienta a forma como o futuro professor deve compreender o ensino, a aprendizagem e sua função social em prol da cidadania, categorizando e classificando as questões educacionais a partir de determinados enquadramentos que o docente em formação passa a ver como os melhores possíveis, sem questioná-los.

Os enunciados presentes na literatura pedagógica estabelecem " [...] regras e padrões que guiam os indivíduos ao produzir conhecimento sobre o mundo" (POPKEWITZ, 1994, p.192) no que se refere à formação de professores, regras e padrões que guiam a docência, inscrevendo atributos de subjetividade (LUKE apud POPKEWITZ, 1994). Considerando isso, ao examinar algumas das formulações discursivas recorrentes na formação de professores, esta análise problematiza o vínculo de determinados discursos com práticas de governamento, isso é, com "ações calculadas para agir tanto sobre os indivíduos quanto sobre o conjunto da população com a finalidade de potencializar a capacidade de alguns para agirem sobre as condutas alheias suas forças, suas atividades, as relações que os sujeitos constituem entre si, etc." (BUJES, 2009, p.270).

Tal vínculo foi sendo estabelecido à medida que nos interrogávamos, mais especificamente, com base em Veiga-Neto (2000), Ó (2009) e muitos outros, como o campo educativo entra em relação direta, em sintonia com o sistema social. Percebendo o notável peso dado à liberdade e à autonomia, que se expressa desde as relações econômicas até a conduta dos indivíduos particulares (Ó, 2009), entendemos que também os discursos pedagógicos estão submetidos a uma dada racionalidade política mais ampla.

A fim de atingir os objetivos propostos para este estudo, utilizamos algumas das contribuições desenvolvidas por Foucault (2008b) a respeito da noção de governamento. Apesar de não ser a educação o objeto de exame do filósofo, o estudo sobre os mecanismos disciplinares que caracterizam as instituições (prisão, fábrica, escola, quartel, hospital) e suas semelhanças ajuda-nos a ampliar o campo de discussão sobre a Pedagogia, sobretudo no que se refere aos discursos sobre a formação. Porém, é preciso advertir que essa noção de governamento, mais do que se referir às instituições disciplinares, indica a proliferação de lugares a partir dos quais se exerce o poder.

Nesse sentido, consideramos importante retomar algumas das discussões feitas por Foucault a respeito do Estado Moderno. VeigaNeto (2000, p. 185) afirma que é especialmente no curso Segurança, território, população que se pode "[...] compreender a Modernidade como resultado da combinação de duas superfícies de emergência: o deslocamento das práticas pastorais e o advento da Razão do Estado". Tal combinação, segundo o autor, estabelece dois jogos antagônicos: o jogo da cidade e o jogo do pastor, que, ao se complementarem, criam condições de possibilidade para a existência do Estado Moderno.

O jogo do pastor tem a disciplina como elemento individualizador - o olhar do soberano instala-se em cada indivíduo. Cada um é governado, ou seja, sua conduta é conduzida para torná-lo pessoa de certo tipo (MARSHALL, 1994). O poder do pastor não se exerce sobre um território, mas sobre um rebanho em deslocamento, sobre uma multiplicidade em movimento (FOUCAULT, 2008b).

Nessa relação, são interessantes as metáforas utilizadas: pastor e rebanho. É o pastor o responsável pelo rebanho, é ele que cuida de cada ovelha em particular. "Uma forma de poder que não cuida apenas da comunidade como um todo, mas de cada indivíduo em particular, durante toda a sua vida" (FOUCAULT, 2008b, p.173).

Para o autor, o poder pastoral pode ser considerado o prelúdio do que vai se desenvolver a partir do século XVI. Os movimentos da Reforma e, depois, da Contra-Reforma geraram novas relações entre o pastor e o rebanho, ocasionando a problemática da pastoral católica e protestante: "como se governar, como ser governado, como governar os outros, por quem devemos aceitar ser governados, como fazer para ser o melhor governador possível?" (FOUCAULT, 2008b, p.118). Intensificaram-se, de um lado, o pastorado em suas dimensões espirituais e, de outro, diferentes tipos de condução dos seres humanos fora do ambiente religioso.

As exigências do capitalismo mercantilista, por sua vez, desafiavam a 
constituição de um saber sobre o Estado, implicando, um pouco mais adiante, a estruturação de novos conhecimentos, referentes primeiramente à Estatística, à Economia e à Demografia, posteriormente, à Saúde Pública, à Psiquiatria, à Psicologia e à Psicanálise (VEIGANETO, 2000). Tratava-se de saberes associados à instauração do jogo da cidade, um poder totalizador voltado para o âmbito civil e da população.

Novas maneiras de governar, mais precisamente a partir do século XVIII, passaram a ser instituídas em relação à população, a fim de produzir mais riqueza, fornecer meios de subsistência suficientes e favorecer o incremento populacional (FOUCAULT, 2004). O Estado passou a reorganizar a forma de utilizar o poder pastoral, assumindo nesse contexto os cuidados com a saúde, o bem-estar, a segurança e a proteção contra acidentes como formas de salvação a serem asseguradas neste mundo. Para Foucault (1995, p. 238), "isto [implicou] que o poder do tipo pastoral, que durante séculos - por mais de um milênio - foi associado a uma instituição religiosa definida, [se ampliasse] subitamente por todo o corpo social; [encontrando] apoio numa multiplicidade de instituições".

Portanto, é no âmbito das artes de governar que se passa a destacar a existência de muitas e diferentes formas de governo: de si, da família e do Estado. Diferentes formas que possuem uma continuidade essencial.

Ao diferenciar essas três formas de governo e sua continuidade, Foucault problematizou: "como introduzir a economia isto é, a maneira de administrar corretamente os indivíduos, os bens, as riquezas no seio de uma família [...] na gestão do Estado?" (2008b, p. 126). A partir dessa problemática, o autor diz que a arte de governar permaneceu bloqueada até quando se tornou possível perceber os problemas específicos da população isolados do quadro jurídico da soberania. A população passa a ser o objeto final do governo organizado, segundo uma racionalidade planejada.

$\mathrm{O}$ gerenciamento familiar passa também a interessar ao domínio político, e o Estado assume parte das funções de manutenção da vida, antes exclusivas da família. A economia em favor dos fenômenos populacionais vai revelar pouco a pouco que a população tem suas próprias características, irredutíveis às da família (FOUCAULT, 2004). Trata-se das características próprias que passam a ser estudadas nas suas regularidades por meio da medição estatística; referem-se aos fenômenos associados com a manutenção e a promoção da vida que ensejam o que Foucault denominou de biopolítica. Os índices de natalidade, mortalidade, de doenças, de produção etc. são alvos dessa tecnologia de poder.

Talvez seja interessante lembrar que, enquanto a disciplina exerce poder sobre o corpo, com efeitos individualizantes, o biopoder se exerce sobre o conjunto da população. Assim, nos deslocamentos pelos quais passam as formas de exercício do poder, não ocorre a substituição de uma sociedade por outra, como observou Foucault (2008b): da sociedade de soberania para a disciplinar e desta para a sociedade de governo. "Temos, de fato, um triângulo - soberania, disciplina e gestão governamental -, uma gestão governamental cujo alvo principal é a população e cujos mecanismos essenciais são os dispositivos de segurança" (p. 143).

A instituição escolar não fica imune aos deslocamentos que ocorrem na sociedade, sendo importante aqui destacar que há pelo menos duas escolas modernas: uma posicionada na lógica disciplinar $^{2}$ e outra na da seguridade (COUTINHO, 2008). "Ou então, melhor ainda: considerando que a incorporação de novos elementos não faz desaparecerem os anteriores, mas os desloca e re-significa seu papel, pode-se dizer que a própria escola foi também governamentalizada" (id., 2008, p. 44). Nesse deslocamento, o sentido dado à liberdade vai significar novas possibilidades de movimento, novas tecnologias, novos saberes e mecanismos de segurança. A escola, como imensa maquinaria cujas práticas sempre estiveram mais ou menos ajustadas ao funcionamento do mundo, tem uma articulação produtiva com a Modernidade (VEIGA-NETO, 2000). E é a partir dos preceitos pedagógicos que dão sustentação aos chamados Projetos de Trabalho que procuramos mostrar como a escola opera tal articulação, cujo principal intuito é "preparar as massas a viverem num Estado governamentalizado" (p. 190).

Sendo o campo pedagógico o cerne da formação de professores, pensamos ser legítimo que tanto um quanto outra possam ser considerados como articulados a uma problemática de governamento $^{3}$, uma vez que estão comprometidos em estruturar "o eventual campo de ação dos outros" (FOUCAULT, 1995, p. 244). Com base nessa premissa, percebemos os professores enredados em práticas que potencializam a conduta própria e alheia, práticas estas que, fazendo parte de um currículo, inscrevem nos sujeitos "certas disposições, modos de pensar, modos de classificar e hierarquizar" (BUJES, 2008, p.109). Em outras palavras, as práticas discursivas dos currículos de formação 
instrumentalizam a maneira como os futuros docentes conduzem o seu trabalho, mas também produzem modos de ver a si mesmos e aos demais implicados no processo de escolarização.

Por tudo isso, mesmo quando os discursos curriculares da formação governam as condutas individuais dos professores, podemos pensar sua conexão com a população, pois a prática dos futuros professores estará voltada para a formação dos alunos - dos cidadãos da sociedade.

A educação docente é, pois, um fenômeno de interesse coletivo, e em alguns discursos que examinamos podemos percebê-la associada à biopolítica da população, o que nos leva à discussão da noção de governamentalidade. Há enlaces dos discursos pedagógicos com as formas, os modos, as táticas de bem exercer o governamento. São discursos que, no âmbito da arte de governar, se valem da verdade produzida pela ciência para potencializar o exercício de poder (BUJES, 2008).

Talvez seja bom aqui lembrar que Foucault (2004) concebe a governamentalidade como um conjunto formado por instituições, procedimentos, análises e reflexões, cálculos e táticas. Composta por arranjos técnicos (notações, computações, avaliações, etc.), por uma conjugação de forças (legais, arquiteturais, financeiras, etc.) e pela utilização de instrumentos (levantamentos, pesquisas, sistemas de treinamento, etc.), ela tem tornado possível, a diferentes autoridades - das mais diversas proveniências -, levar a efeito programas de administração social que têm por finalidade regular não só as decisões, mas as ações individuais, grupais, institucionais.

A governamentalidade implicaria, assim, que o poder, para ser exercido racionalmente e tornar os sujeitos passíveis de serem governados, precisaria se valer de uma série de mecanismos/estratégias, e no seu âmbito inventaram-se o que Foucault chamou de tecnologias de poder, os meios que se valem as autoridades (de todas as ordens) para instrumentalizar e normalizar as condutas.

O termo governamentalidade, é associado por Fymiar (2009) a novas formas de pensar o exercício do poder com o paulatino processo de governamentalização do Estado, correspondendo a mutações que ocorreram na forma de pensar as finalidades do Estado, o exercício do poder, a vida econômica e, em especial, a população quando esta passou a ser vista como um campo de intervenção. A ampla escolarização das crianças pode ser situada no âmbito destes deslocamentos que alteram as formas como as relações de poder atingem os indivíduos. No movimento de organização dos Estados liberais na passagem dos séc. XVIII para o XIX, estendendo-se por parte do séc. XX, segundo Rose (1999), evidencia-se a criação de uma nova matriz de racionalidade, que orientou a invenção de uma série de tecnologias, envolvendo cálculos e estratégias, para intervir em novos campos que se ofereciam ao exercício do poder: a economia, a saúde e os hábitos da população, a civilidade das massas, a educação.

As tecnologias analisadas por Foucault permitem-nos tematizar a constituição subjetiva dos docentes por discursos, como os dos Projetos de Trabalho, sustentados nos ideais de liberdade, interesse e aprendizagem. Por meio de pretensões de verdade dos discursos pedagógicos, operam-se relações de poder-saber que atingem uma população sob um Estado moderno liberal. É com base em ideais como esses que a educação escolarizada tem funcionado como uma estratégia de governamento dos sujeitos.

\section{A racionalidade neoliberal na constituição do sujeito professor e a adoção dos Projetos de Trabalho}

De acordo com Coutinho (2008), a segunda escola moderna, aquela com a qual convivemos hoje, encontra-se numa relação imanente, com acontecimentos da sociedade, como a "revolução industrial, o Iluminismo, o transcendental kantiano, a idéia de futuro como progresso, a fisiocracia e o liberalismo", (p.34) entre outros. $\mathrm{O}$ poder disciplinar continua operando em uma nova lógica, na qual a mobilidade é o elemento diferencial em relação à ordenação tipicamente disciplinar e às formas que começam a se instituir no século XVIII (ibidem.). Entre essas formas, no que se refere ao campo da educação, estão as modificações em relação aos espaços, rotinas e recursos da sala de aula. No entanto, não são apenas modificações em termos estruturais que podemos perceber nos discursos pedagógicos do século XVIII: há a problematização de alcançar a liberdade e a autonomia, antes que coação, direção e heteronomia (NOGUERA-RAMÍREZ, 2008).

Nessa perspectiva, em contraposição aos métodos baseados na repetição e memorização utilizados pela escola moderna numa lógica disciplinar, destacam-se as ideias preconizadas por Rousseau, filósofo suíço que defende as experiências realizadas pelo próprio aluno.

Os pressupostos rousseaunianos não se inseriram de imediato no campo da prática: foi necessária toda a 'revolução romântica', toda a imposição de uma visão positiva da ciência e mais um século de intervalo para que eles revivessem 
num núcleo 'renovador' da Pedagogia, no alvorecer do século XX.

Trata-se do Movimento da Escola Nova, que tomou proporções peculiares em diferentes localidades. Acontecimentos sociais marcados pelos efeitos da Revolução Industrial objetivavam uma sociedade mais democrática, atribuindo à escola um importante papel nessa tarefa. Isso pode ser percebido, por exemplo, quando alguns autores escolanovistas defendem a escola popular e de massas, que, além de democrática, deve estar preparada para o desenvolvimento tecnológico "o que a nutrição e a reprodução representam para a vida fisiológica, a educação é para a vida social" (DEWEY apud LOURENÇO FILHO, 1965, p.7).

As orientações didáticas, até então voltadas à constituição de um indivíduo dócil e obediente, deslocam agora o seu interesse em direção a outro tipo de sujeito, autorregulado por seu próprio interesse e desejo. Há, segundo Noguera-Ramírez (2008), “[o] deslocamento da preocupação pela instrução, o ensino, a disciplina, para a 'formação', a 'educação'” (p.11), uma vez que se referem a este novo tipo de sujeito, “[...] produto da ação individual para atingir a virtude, a moralidade, no marco das novas ideias de cidadania" (p.12).

Para Foucault (2008b), há uma sintonia entre variados discursos e a forma de organização política e econômica das sociedades, relacionada, na época, com o liberalismo, representado pela máxima: [...] deixar as pessoas fazerem, as coisas passarem, as coisas andarem, laisser-faire, laisser-passer e laisser-aller [...]"(p.62-63).

Nos discursos pedagógicos, percebe-se o enfoque dado ao desenvolvimento das crianças, que consistiria em deixá-las seguir um caminho seu, pessoal, orientado por suas escolhas (mas, de algum modo, dirigido pela natureza). $\mathrm{O}$ Movimento da Escola Nova, por exemplo, desloca o eixo da reflexão educativa em direção à criança. A escola, como uma das instituições que se encarrega de controlar e disseminar novas tecnologias, vai sendo produzida no campo político de discursividade liberal.

John Dewey foi o principal representante deste Movimento e vai dar sustentação ao enfoque dos Projetos, tendo em conta o aspecto inovador dado à capacidade de pensar. As teorizações desse autor articulam-se à racionalidade governamental liberal, já que tratam o indivíduo como sujeito de uma natureza em desenvolvimento que será favorecida pela contínua reorganização e reconstrução da experiência, para a qual a liberdade é condição essencial (TEIXEIRA, 1965).
Nesse sentido, é possível estabelecer relações entre uma orientação curricular que privilegia os Projetos de Trabalho, principal objeto de análise deste estudo, a formas de governamento dirigidas aos sujeitos ideais no liberalismo e no neoliberalismo. Nos discursos dos livros dos cursos de Pedagogia aqui analisados, os Projetos de Trabalho são apresentados como a tentativa que melhor responderia às exigências de reorganização da informação no âmbito da escola para atender às demandas da realidade social, econômica e cultural contemporânea. Sua função, segundo Hernández e Ventura (1998, p.61),

\section{é favorecer a criação de estratégias de organização dos conhecimentos escolares em relação a: 1) o tratamento da informação, e 2) a relação entre os diferentes conteúdos em torno de problemas ou hipóteses que facilitem aos alunos a construção de seus conhecimentos, a transformação da informação procedentes dos diferentes saberes disciplinares em conhecimento próprio (grifos dos autores).}

Nessa perspectiva, os Projetos são apresentados como estratégias pedagógicas que visam a transgredir, "explorar novos caminhos que permitam que as escolas deixem de ser formadas por compartimentos fechados, horários fragmentados, arquipélagos de docentes e passem a converter-se numa comunidade de aprendizagem" (HERNÁNDEZ, 1998, contracapa). Assim, essa metodologia apresentase como diferenciada das demais, por pretender construir intercâmbios de culturas e biografias em sala de aula, "ultrapassar os limites das disciplinas" (SANTOMÉ, 1998, p.25). Os discursos pedagógicos da escola, no presente, declaram a possibilidade de cada aluno se autodesenvolver. O forte desejo de transformar o aluno em um sujeito capaz de solucionar problemas e responsável pelas suas escolhas, insere-o numa comunidade de aprendizagem onde se diz que - com o empenho necessário e a orientação pedagógica adequada - ele será capaz de exercer e cumprir seu papel de cidadão, de constituir-se como sujeito moral e intelectualmente autônomo, de preparar-se para exercer determinadas funções na sociedade e de tornar-se um trabalhador competente.

Apesar de os Projetos de Trabalho darem sequência à defesa de uma prática de trabalho que valoriza o papel decisório dos alunos desde Dewey, analisar isso nos discursos vigentes não 
significa falar da mesma coisa, uma vez que tais discursos estiveram sujeitos a condições materiais de enunciação muito distintas.

É preciso então compreender o deslocamento da produção para o consumo, da (re)significação da liberdade como algo natural e espontâneo - no liberalismo - para um objeto de consumo - no neoliberalismo. De uma lógica que reproduz passamos a uma outra lógica, que cria, inventa, inova. O trabalho ultrapassa a atividade física. É preciso utilizar diferentes estratégias, ser criativo e fazer diferença. A educação tem um papel importante na orientação dessas mudanças. E não é por acaso que na educação percebemos os efeitos de atravessamento das ideias de "consumir", gerir informações, flexibilizar, criar e desenvolver competências. A escola moderna não dá mais conta de seu papel na formação do sujeito para uma época neoliberal e passa a reorganizar e reconfigurar seus processos educativos. A organização curricular proposta por Sacristán (2000) e Santomé (1998), bem como a retomada dos Projetos de Trabalho proposta por Hernández (1998) e Hernández e Ventura (1998), insere-se na matriz discursiva associada a uma racionalidade política neoliberal.

Os Projetos de Trabalho elevam a máxima preconizada de levar o sujeito a reaprender $a$ aprender ao longo de sua vida. Cada um descobre que tem responsabilidade na sua própria aprendizagem - o sujeito empresário de si (VEIGA-NETO; SARAIVA, 2009) -, sendo apto a desenvolver suas capacidades na tentativa de melhor solucionar os desafios e resolver problemas de seu cotidiano. Aprender, nesse contexto, significa ter cada vez mais liberdade para gerir o próprio caminho, fazer escolhas, responsabilizar-se por elas na busca de realização pessoal, mas, sobretudo, inserir-se produtivamente num mundo voltado para o consumo e para a competição. Com o objetivo de produzir capital humano, dotado de aptidões para os novos tipos de trabalho, a educação teria reforçada sua posição de grande empreendimento na produção de novos sujeitos.

E aqui é preciso dar um destaque especial, diante do objeto desta análise, ao professor como figura emblemática do esforço empreendedor: "[...] 'serão os professores aqueles que em definitivo, mudarão o mundo da escola, entendendo-a" (HERNÁNDEZ; VENTURA, 1998, p.27).

Essa individualização, que implica a responsabilização do professor, estimula cada vez mais a sua procura de embasamento, de leituras na busca de legitimação. Enfatiza-se a ele, de forma significativa, um vocabulário composto de termos, tais como: flexibilidade, espírito inovador, trabalho em equipe, entusiasta, facilitador, autonomia, aprender a aprender. Essas palavras ou expressões funcionam como ideias-chave, peças de uma narrativa, conjunto da mesma natureza, para constituir a referência a partir da qual cada professor deverá se examinar e fazer a reflexão sobre os modos como exercerá a sua docência.

Ser flexível, por exemplo, seria o traço que possibilitaria ao professor relacionar as questões desse tempo, os interesses dos alunos, traduzindo-os na mudança da organização dos conhecimentos escolares. Essa flexibilidade aparece, tanto em Santomé como em Hernández, de forma muito semelhante, como uma hipotética sequência, alguns passos, não fixos, "mas [que] serve [m] de fio condutor para a atuação docente em relação aos alunos" (HERNÁNDEZ, 1998, p.81):

Parte-se de um tema ou de um problema negociado com a turma; inicia-se um processo de pesquisa; buscam-se $e$ selecionam-se fontes de informação; estabelecem-se critérios de ordenação e de interpretação das fontes; recolhem-se novas dúvidas e perguntas; estabelecemse relações com outros problemas; representa-se o processo de elaboração do conhecimento que foi seguido; recapitula-se (avalia-se) o que se aprendeu; conecta-se com um novo tema ou problema (id., 1998, p.81).

Há, em contrapartida à flexibilidade, prescrições que orientam o exame das ações dos professores. E, assim, arriscamo-nos a dizer que os discursos sobre os Projetos de Trabalho operam no interior das práticas de formação de professores, no sentido de criar sujeitos governáveis através da utilização de várias técnicas que têm por finalidade controlar, normalizar e moldar a conduta desses futuros profissionais. Há constante referência à relevância da atuação do professor na construção de um aluno, de um sujeito ideal capaz de analisar e interpretar o mundo em que vive. De sujeitos ideais que

são levad[os] a reconstituir em narrativas $e$ textos, as experiências vividas reconhecendo-se como 'protagonistas' das mesmas. Nesse tipo de experiência há um constante incitamento para que [eles] se vejam, se narrem, se julguem, mas mais do que isso, há uma recorrência tenaz e 
oportunidades sempre reiteradas para que ajam no sentido de transformar-se (BUJES, 2009, p.280).

A elaboração do índice, por exemplo, tem um forte papel nesse processo. Trata-se de um instrumento que possibilita ao aluno antecipar o desenvolvimento do Projeto, planejar as diferentes atividades a serem realizadas, prevendo ações e o envolvimento do grupo. São os alunos que realizam as escolhas e tomam as iniciativas do trabalho a ser realizado. No entanto, como apontam Veiga-Neto e Saraiva (2009, p.198), "[devem] encaixar-se dentro de um recorte estabelecido pelo professor. A vinculação dos Projetos ao currículo não permite uma escolha assim tão livre, de modo que o interesse da criança é produzido por intervenções do professor". De certa forma, o índice gerencia e programa todas as ações feitas - a serem realizadas e as que não foram realizadas - nesse mecanismo de controle, automonitoramento e confissão.

O portfólio é outra estratégia dos Projetos a ser analisada. É neste que ficam reunidos os registros das hipóteses, das construções individuais ou coletivas feitas durante todo o desenvolvimento do Projeto. É uma modalidade de avaliação vinculada à evolução do processo de aprendizagem. Trata-se de uma estratégia de governo que afeta as aspirações e desejos pessoais de forma indireta, maximizando as capacidades intelectuais:

\begin{abstract}
[...] acumulando registros contínuos do progresso dos estudos [...] se pode utilizar não só para manter os estudantes ativamente implicados em seu próprio progresso (e, portanto, comprometendoos em manter seus esforços para alcançar $o$ êxito), mas sim também para "deixar frios" os estudantes que estão tendo dificuldades com seus estudos, baixando suas expectativas e tendo que assumir por si mesmos, momento a momento, fragmento a fragmento, a natureza e a extensão de seus fracassos (HERNÁNDEZ, 1998, p.98).
\end{abstract}

O portfólio possibilita indicar os momentos-chave das aprendizagens conquistadas, superadas e a superar de ambos os sujeitos escolares: alunos e professores. $\mathrm{O}$ anseio de que possam, juntos, reaprender a aprender vai possibilitar trajetos e aspirações de próximos desejos, traçando, segundo Rose (1998, p.44), “a distância entre aquilo que somos e aquilo que podemos nos tornar".

Nesse sentido, poderia se dizer que a análise dos Projetos de Trabalho, central nos discursos curriculares de formação de professores, articulada à governamentalidade neoliberal, incita a constituição de novos sujeitos. É sobre estes que está o grande investimento da contemporaneidade, uma vez que empreender se associa aos processos de ensino e aprendizagem. Investir na proposta dos Projetos de Trabalho seria investir em capital humano, promover a maximização dos potenciais de cada um, não sendo apenas útil ao desenvolvimento do trabalho, mas ao crescimento pessoal ao longo da vida.

Por todas essas razões, ao nos interessarmos pelos discursos curriculares da formação docente, foi possível destacar a sua estreita vinculação com as práticas de constituição do sujeito professor na atualidade. Problematizar tais discursos possibilitou que os percebêssemos atravessados por relações de poder, em diferentes momentos e contextos, e reforçou nossa convicção de que fizeram e fazem parte dos processos produtivos da sociedade, permitindonos entender sob um prisma bem menos idealista as aspirações da formação docente deste nosso tempo.

E é nesse sentido que desejamos enfatizar que não tivemos a pretensão de apresentar um estudo que traçasse direções para a formação docente nem demarcar um campo de convicções ou soluções para os problemas educacionais. Substituir um modo de pensar por outro não garante a promoção de uma investigação mais comprometida e arguta (BUJES, 2008). Nossos propósitos são outros - talvez um tanto menos ambiciosos, como cremos ter explicitado ao longo deste texto -, uma vez que nos afastamos das crenças dominantes acerca da verdade e do progresso que ainda marcam o campo pedagógico. Acreditamos ser produtivo pensar em como chegamos a conceber a relevância dos Projetos na atividade docente, para depois contestá-los e até mesmo desconstruí-los, no sentido atribuído por Veiga-Neto (2007) de abrir outros espaços, espaços de liberdade, indagação e mudança.

\section{Referências Bibliográficas}

BUJES, Maria Isabel E. Infância e Maquinarias. (2001). Tese (Doutorado em Educação) Faculdade de Educação, Universidade Federal do Rio Grande do Sul, Porto Alegre, 2001. 
BUJES, Maria Isabel E. Para pensar pesquisa e inserção social. Revista Eletrônica de Educação (UFScar), v.2, 2008, p.106-124. Disponível em: <http://www.reveduc.ufscar> Acesso em: 06 fev. 2010.

BUJES, Maria Isabel E. Manuais Pedagógicos e Formação docente: elos de poder/saber. Currículo sem fronteiras, v.9, n.1, jan./jun.2009, p.267-288. Disponível em: <www.curriculosemfronteiras.org> Acesso em: 10 mar. 2010.

COUTINHO, Karyne Dias. A emergência da Psicopedagogia no Brasil. (2008). Tese (Doutorado em Educação) - Faculdade de Educação, Universidade Federal do Rio Grande do Sul, Porto Alegre, 2008.

DEWEY, John. Vida e Educação. $5^{\text {a }}$ ed. São Paulo: Melhoramentos, 1965.

DÍAZ, Mario. Foucault, docentes e discursos pedagógicos. In: SILVA, Tomaz T. da (Org). Liberdades reguladas: a pedagogia construtivista e outras formas de governo do eu. Petrópolis: Vozes, 1999, p.14-29.

FIMYAR, Olena. Governamentalidade como Ferramenta Conceitual na Pesquisa de Políticas Educacionais. Educação \& Realidade, Porto Alegre, maio/ago., 2009, p.35-56.

FOUCAULT, Michel. O Sujeito e o Poder. In: RABINOW, P.; DREYFUS, H. Michel Foucault, uma trajetória filosófica: para além do estruturalismo e da hermenêutica. Rio de Janeiro: Forense Universitária, 1995, p.231-249.

FOUCAULT, Michel. A ordem do discurso. São Paulo: Edições Loyola, 1996.

FOUCAULT, Michel. A governamentalidade. In: FOUCAULT, Michel. Microfísica do poder. Rio de Janeiro: Graal, 2004, p. 277-293.

FOUCAULT, Michel. Vigiar e Punir: histórias da violência nas prisões. 34. ed. Rio de Janeiro: Vozes, 2008a.

FOUCAULT, Michel. Segurança, território, população: curso no Collège de France (19771978). São Paulo: Martins Fontes, 2008b.

HERNÁNDEZ, Fernando. Transgressão e mudança na educação: os projetos de trabalho. Porto Alegre: Artes Médicas, 1998.
HERNÁNDEZ, Fernando; VENTURA, Montserrat. A organização do currículo por projetos de trabalho: o conhecimento é um caleidoscópio. Porto Alegre: Artes Médicas, 1998.

LARROSA, Jorge. Notas sobre a experiência e o saber de experiência. Revista Brasileira de Educação, nº. 19, Jan/Fev/Mar/Abr., 2002, p.2028.

LOURENÇO FILHO, Manuel Bergström. Prefácio da $5^{\text {a }}$ edição. In: DEWEY, John. Vida e Educação. $5^{\mathrm{a}}$ ed. São Paulo: Melhoramentos, 1965, p.7-11.

MARSHALL, James. Governamentalidade e Educação Neoliberal. In: SILVA, Tomaz Tadeu (org.). $\quad \mathbf{O}$ sujeito da educação: estudos foucaultianos. Petrópolis: Vozes, 1994, p. 21-34.

NOGUERA-RAMÍREZ, Carlos Ernesto. A invenção do "Homo educabilis". Da sociedade disciplinar para a sociedade da aprendizagem. (2008). Proposta de Tese (Doutorado em Educação) - Faculdade de Educação, Universidade Federal do Rio Grande do Sul, 2008.

Ó, Jorge Ramos do. A Governamentalidade e a História da Escola Moderna: outras conexões investigativas. Educação \& Realidade, Porto Alegre, maio/ago., 2009, p.97-118.

POPKEWITZ, Thomas S. História do Currículo, Regulação Social e Poder. In: SILVA, Tomaz Tadeu. O sujeito da Educação: Estudos foucaultianos. 5 ed., Petrópolis: Vozes, 1994, p.173-210.

POPKEWITZ, Thomas S. Uma perspectiva comparativa das parcerias, do contrato social e dos sistemas racionais emergentes. In: TARDIF, Maurice; LESSARD, Claude. O ofício de professor: história, perspectivas e desafios internacionais. Petrópolis: Vozes, 2008, p.234254.

POPKEWITZ, Thomas S. OLSSON, Ulf; PETERSSON, Kenneth. Sociedade da Aprendizagem, Cosmopolitismo, Saúde Pública e Prevenção à Criminalidade. Educação \& Realidade, Porto Alegre, maio/ago., 2009, p.7396.

POÇAS, Jaqueline de Menezes Rosa. Projetos de Trabalho e Formação Docente: novos sujeitos, novas práticas de governamento. (2010). 
Dissertação (Mestrado em Educação) Universidade Luterana do Brasil, Canoas, 2010.

ROSE, Nikolas. Powers of freedom: reframing political thought. Cambridge/New York: Cambridge University Press, 1999.

SACRISTÁN, J. Gimeno. O currículo: uma reflexão sobre a prática. Porto Alegre: Artes Médicas, 2000.

SANTOMÉ, Jurjo Torres. Globalização e interdisciplinaridade: o currículo integrado. Porto Alegre: Artes Médicas, 1998.

TEIXEIRA, Anísio. A Pedagogia de Dewey: estudo introdutório por Anísio Teixeira. In: DEWEY, John. Vida e Educação. $5^{\text {a }}$ ed. São Paulo: Melhoramentos, 1965, p.13-41.

VEIGA-NETO, Alfredo. Educação e Governamentalidade neoliberal: novos dispositivos, novas subjetividades. In: PORTOCARRERO, Vera; CASTELO BRANCO, Guilherme (org). Retratos de Foucault. Rio de Janeiro: NAU Editora, 2000, p. 179-217.

VEIGA-NETO, Alfredo José da. Coisas de governo... In: RAGO, M.; ORLANDI, L.B.L.; VEIGA-NETO, A. (Orgs.). Imagens de Foucault e Deleuze - ressonâncias nietzschianas. Rio de Janeiro: DP\&A, 2002.

VEIGA-NETO, Alfredo José da. Foucault \& a Educação. 2.ed., Belo Horizonte: Autêntica, 2007.

VEIGA-NETO, Alfredo; SARAIVA, Karla. Modernidade Líquida, Capitalismo Cognitivo e Educação Contemporânea. Educação \& Realidade, Porto Alegre, maio/ago., 2009, p.187201. 


\section{Notas}

1 Por similar, entendemos disciplinas que tratam dos temas didáticos, mas recebem denominações tais como: Organização do Trabalho Pedagógico, Organização Escolar, Prática Pedagógica Interdisciplinar, Ação Pedagógica na Educação Infantil e Anos Iniciais, Ação Pedagógica na Educação Básica, Projetos Educativos Interdisciplinares, etc.

2 Nessa lógica, o enfoque no ensino e na instrução reforça a importância do mestre, centro da ação pedagógica, sobre a conduta das crianças. O conjunto das ordens, da organização dos espaços, dos tempos, da estrutura dos conteúdos, irá constituir uma rotina inflexível na obtenção da obediência e disciplina. Modelo pedagógico que se sucede no ensino dos jesuítas e se generaliza a partir do século XVIII, através da consolidação das idéias propagadas na Didática Magna de Comenius.

3 A fim de evitar problemas léxicos com a palavra governo, valemo-nos do termo utilizado por Bujes (2001) e Veiga-Neto (2002): governamento. "Justifico a utilização do termo com a intenção de diferenciá-lo de governo - como uma instância de controle político, como instituição a quem cabe o exercício de autoridade -, do ato que se exerce sobre uma pessoa ou que ela exerce sobre si mesma, para controlar suas ações" (BUJES, 2001, p.73).

\section{Sobre as autoras:}

Jaqueline de Menezes Rosa: Mestre em Educação, professora do Curso de Pedagogia da Universidade Luterana do Brasil (Canoas/RS).

Maria Isabel Edelweiss Bujes: Doutora em Educação, professora do Programa de Pós-Graduação em Educação da Universidade Luterana do Brasil (Canoas/RS) e pesquisadora da infância. 